Annales Geophysicae (2002) 20: 1869-1876 (c) European Geosciences Union 2002

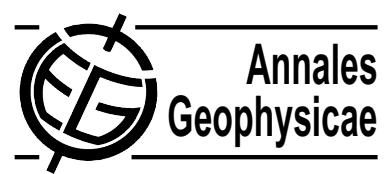

\title{
Observations on Stratospheric-Mesospheric-Thermospheric temperatures using Indian MST radar and co-located LIDAR during Leonid Meteor Shower (LMS)
}

\author{
R. Selvamurugan ${ }^{1}$, C. V. Devasia ${ }^{2}$, A. R. Jain ${ }^{1}$, C. Raghava Reddi ${ }^{3}$, P. B. Rao ${ }^{1}$, and R. Sridharan ${ }^{2}$ \\ ${ }^{1}$ National MST Radar Facility, Tirupati, 517 502, India \\ ${ }^{2}$ Space Physics Laboratory, Vikram Sarabhai Space Centre, Trivandrum 695 022, India \\ ${ }^{3}$ Andhra University, Waltair, Visakapatnam, India
}

Received: 18 June 2001 - Revised: 26 November 2001 - Accepted: 6 February 2002

\begin{abstract}
The temporal and height statistics of the occurrence of meteor trails during the Leonid meteor shower revealed the capability of the Indian MST radar to record large numbers of meteor trails. The distribution of radio meteor trails due to a Leonid meteor shower in space and time provided a unique opportunity to construct the height profiles of lower thermospheric temperatures and winds, with good time and height resolution. There was a four-fold increase in the meteor trails observed during the LMS compared to a typical non-shower day. The temperatures were found to be in excellent continuity with the temperature profiles below the radio meteor region derived from the co-located Nd-Yag LIDAR and the maximum height of the temperature profile was extended from the LIDAR to $\sim 110 \mathrm{~km}$. There are, however, some significant differences between the observed profiles and the CIRA-86 model profiles. The first results on the meteor statistics and neutral temperature are presented and discussed below.
\end{abstract}

Key words. Atmospheric composition and structure (pressure, density, and temperature) History of geophysics (atmospheric sciences) Meteorology and atmospheric dynamics (middle atmosphere dynamics)

\section{Introduction}

The Leonid Meteor Stream (LMS), having its origin from the Leo constellation located at $17^{\circ}$ north declination and $11^{\circ}$ right ascension of the celestial sphere, exhibits substantial increase of meteor fluxes in the Earth's atmosphere at intervals of about 33 years. Data were acquired with ground-based $\mathrm{HF}$ and VHF radars at Trivandrum $\left(8.5^{\circ} \mathrm{N}, 77^{\circ} \mathrm{E}\right)$, partial reflection radar at Tirunelveli $\left(8.6^{\circ} \mathrm{N}, 77.4^{\circ} \mathrm{E}\right)$ and Ionosondes at Trivandrum and SHAR $\left(13.7^{\circ} \mathrm{N}, 80.2^{\circ} \mathrm{E}\right)$ along with the Indian MST radar and co-located LIDAR at Gadanki $\left(13.5^{\circ} \mathrm{N}, 79.2^{\circ} \mathrm{E}\right)$ during the Leonid's Meteor Shower ac-

Correspondence to: R. Selvamurugan

(Selvastella@indiatimes.com) tivity period of 16-20 November 1999. In addition, two RH-300 rockets were flown from SHAR to measure the neutral and ion composition, and electron and ion densities and temperatures. However, the scope of this paper is limited to observational results from the Indian MST radar and the co-located LIDAR. The Indian MST radar was used for patrolling the enhancement of meteor fluxes during the period of LMS enhanced activity. The co-located LIDAR, operating at $532 \mathrm{~nm}$, has been used to make measurements of atmospheric temperature in the height range of $30-80 \mathrm{~km}$ region from the photon count, which is proportional to the molecular density, presuming that the atmosphere is in hydrostatic equilibrium. Meteor trails are used for the determination of the atmospheric diffusion coefficient following the method described in the literature (Hocking, 1999). In fact, the detection of meteor traces, and thus, the estimation of diffusion coefficient began as early as 1952 (e.g. Huxley, 1952; Kaiser, 1953; Greenhow and Neufeld, 1955), persisting until today with studies using recent developments (Tsutsumi et al., 1994; Raghava Reddi et al., 1995; Chilson et al., 1996; Hocking, 1999; Hocking et al., 1997, 2001). The strength of the meteor radar echoes depends on the power aperture product and operating frequency of the radar. The MST radar, having a peak power of $2.2 \mathrm{MW}$ and a narrow antenna beam width, was found to give finer details of the meteor echo. The Doppler shift of the meteor trail echoes gives the line of sight velocity of the echoing region. The exponential decay rate of the meteor echoes give the ambipolar diffusion coefficient, which, in turn, can be interpreted in terms of temperature of the atmosphere in the height range of $80-110 \mathrm{~km}$, where sufficient number of meteor trails are observed. This paper presents the temporal and altitude distribution of Leonid's meteor occurrences obtained during the LMS period, as well as the method of deriving a diffusion coefficient and also of estimating the Mesospheric temperature. Simultaneous measurements of LIDAR and Indian MST radar are used to obtain the atmospheric temperature in the Mesospheric and Lower Thermospheric (MLT) region during this period. 
Table 1. Date and time of Leonid Meteor Shower (LMS) observation using Indian MST radar

\begin{tabular}{cccc}
\hline Start Date & Start Time & Stop Date & Stop time \\
\hline 16.11 .99 & $02: 03: 32$ & 16.11 .99 & $07: 11: 06$ \\
16.11 .99 & $22: 13: 38$ & 17.11 .99 & $05: 50: 48$ \\
17.11 .99 & $22: 16: 58$ & 18.11 .99 & $05: 22: 21$ \\
18.11 .99 & $22: 07: 00$ & 19.11 .99 & $05: 30: 33$ \\
19.11 .99 & $22: 27: 20$ & 20.11 .99 & $05: 09: 27$ \\
\hline
\end{tabular}

\section{Observations}

The Indian MST radar was operated in meteor mode to observe Leonid meteor shower echoes from 16-20 November 1999 between 22:00-06:00 LT (see Table 1 for details). The technical details of the radar system are given by Rao et al. (1995). To make a truly representative measurement of the meteor occurrence rate, the volume of the atmosphere probed by the radar should be larger. This demands a large width for the radar beam. In order to infer the height of the meteor echo reliably from the measured slant range, and the zenith angle of the radar beam, it is necessary to have a narrow radar beam. In this experiment, four rows of antennae, each with 32 Yagi arrays aligned along EW or NS directions were used and the phases of the sub-arrays were harnessed to produce a main beam at a zenith angle of $20^{\circ}$. Thus, a fan beam of $40^{\circ} \times 3^{\circ}$ was produced. Data were collected alternately with the EW and NS sub-arrays, both oriented at a $20^{\circ}$ zenith angle towards north or east, depending on the array chosen. Sporadic E (Es) echoes were received frequently from the northward beam, and these echoes spread over many range bins. One frame of data was obtained with the northward beam and nine frames of data were recorded with the eastward beam and this sequence was repeated. Thus, successive sets of data frames of 10 each contained one from the northward beam and the remaining from the eastward beam. The radar parameters were selected such that the Pulse Repetition Frequency (PRF) was $1000 \mathrm{~Hz}$, with a pulse width of $8 \mu \mathrm{s}$. Each data frame had 25 range bins at $1.2 \mathrm{~km}$ range intervals from $79.9 \mathrm{~km}$ to $108.8 \mathrm{~km}$. Four successive Inphase (I) and Quadrature (Q) samples for each range bin were coherently averaged, making the effective sampling interval of $4 \mathrm{~ms}$. Each data frame had continuous data for $2.048 \mathrm{~s}$ similar to that employed by Raghava Reddi and Nair (1994). The system required a set-up time of a few seconds for each frame, and so the successive data frames are not continuous in time. The peak power radiated by the four sub-arrays was about $480 \mathrm{~kW}$, which is large enough to deem the system powerful for meteor patrolling. The data were processed off-line to separate the frames containing signatures of meteor echoes. When the echo in one or more range bins exceeded an average floor noise of a specific threshold $(1.35 \mathrm{~V})$ for at least three successive transmitter pulses, then the frame is identified to contain backscattered echo from the meteor trails and is subsequently archived. On the average, about $10 \%$ of the frames contained meteor echoes in one or more range bins during non-shower periods (Raghava Reddi and Nair, 1998). During LMS period, the meteor echoes were found to be very frequent in time and height.

The co-located pulsed LIDAR with an Nd-Yag laser head radiating at $532 \mathrm{~nm}$ at $20 \mathrm{~Hz}$ was used in the backscatter mode to receive molecular scattered signals from the 30$80 \mathrm{~km}$ height region. Temperature data from LIDAR could be obtained only on the night of 17-18 November 1999, as the sky was partly cloudy on the other nights during the LMS period. The pressure deduced from the hydrostatic equation and the molecular density obtained using LIDAR from the photon counts are used to retrieve the temperature profile. The standard inversion code developed to deduce the temperature profile from the photon count verses height profile (Rao et al., 1999) was used. The hydrostatic equilibrium and pressure at the Mesopause level are taken from the model. It may be mentioned here that, since the temperature estimates are made using the relative density distribution with height, the assumed pressure of the Mesopause affects the profile (if at all) in the first $1 \mathrm{~km}$ only and, therefore, the profile below $79 \mathrm{~km}$ becomes literally independent of the assumed Mesopause pressure. The deduced temperature profile using the LIDAR $(30-80 \mathrm{~km})$ data is combined with the temperature profile determined using MST radar data $(80-110 \mathrm{~km})$ to obtain a continuous temperature profile for the height region of $30-110 \mathrm{~km}$.

\section{Method of analysis}

\subsection{Meteor occurrences}

During LMS, many frames contained more than one meteor trail data, at a given time. The hourly count of meteors was multiplied by a factor given by the ratio of the number of data frames per hour $(\approx 1758)$ that would be recorded, if the data were recorded continuously without any set-up time between consecutive frames, and the number of frames per hour actually recorded $(\approx 720)$. The number of meteors that would be recorded if the radar acquired data continuously were used to study the occurrence statistics of the meteor trails.

\subsection{Mesospheric-lower thermospheric temperature}

Only underdense $\left(<10^{12} \mathrm{ele} / \mathrm{m}^{3}\right)$ meteor trails (Fig. 1) exhibiting an exponential decay of amplitude by ambipolar diffusion of the ionization trail were used to compute an ambipolar diffusion coefficient and the temperature of the atmosphere around the meteor trail producing the radar echo. The trail, soon after its formation, is at a very high temperature and expands rapidly to attain thermal equilibrium with the ambient atmosphere in a few tens of milliseconds. During this phase, the echo amplitude increases and the Doppler frequency is also large. The radar echo amplitude may remain constant for varying time duration after the initial expansion and then decreases exponentially to reach the floor 


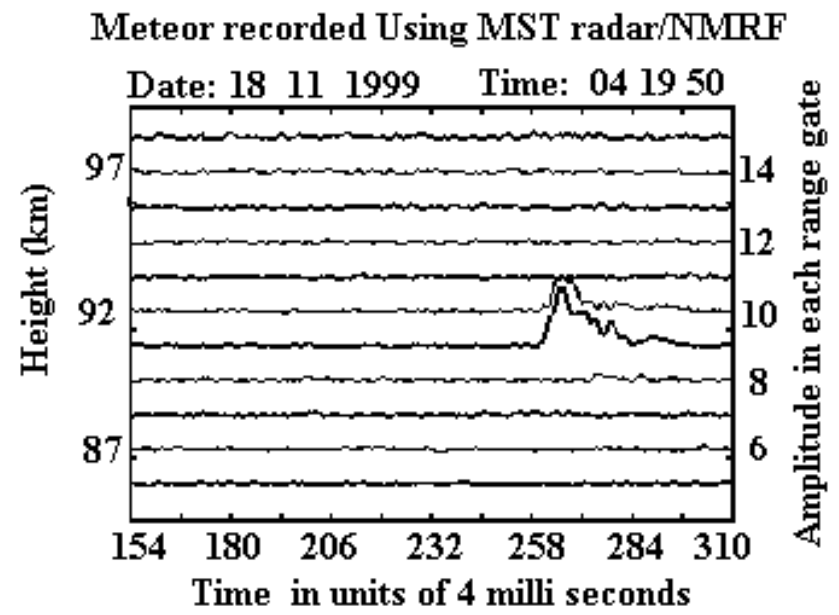

Fig. 1. Time variation of MST radar echo from a typical underdense Meteor trail.

noise. This decrease is essentially due to a decrease in coherency among the scattered signals while the trail slowly expands due to ambipolar diffusion. During this phase of the trail, it moves bodily with the surrounding atmosphere while simultaneously expanding, and, hence, the Doppler shift corresponds to the line of sight velocity of the surrounding atmosphere. The rate of decrease in the meteor echo amplitude due to ambipolar diffusion can be represented by

$A_{t}(t+\Delta t)=A_{0}(t) \exp -\left(\frac{16 \pi^{2} D \Delta t}{\lambda^{2}}\right)$,

where $t$ is the time elapsed for the amplitude to and from $A_{0}(t)$ at $t=0$, to $A_{t}$ at $(t+t)$, and $\lambda$ is the radar wavelength $(5.66 \mathrm{~m}$ in the case of the MST radar at Gadanki). Moreover, the diffusion coefficient $D$ is directly proportional to the background Mesospheric temperature $(T)$ and inversely proportional to the molecular weight of the atmospheric molecules $(\mathrm{m})$ and collision frequencies of the ions produced due to the meteor ablation with neutral molecules $\left(v_{i n}\right)$ (Raghava Reddi et al., 1995). This can be written as

$D=\frac{k T}{v_{i n} m}$,

where $k$ is the Boltzmann's constant. To obtain the temperature from the above equation, it becomes essential to use the model values of the ion-neutral collision frequency $\left(v_{i n}\right)$ and the mean molecular weight $(m)$ of the atmospheric ions at the height of the echoing region of the meteor trail. In general, the dominant atmospheric species is taken up to represent $m$. In addition to causing an ionized trail of the atmospheric species, the meteor ablation also releases significant amounts of heavy metallic atoms, such as $\mathrm{Fe}$ and $\mathrm{Ca}$, into the atmosphere. Further, the ion neutral collision frequency in Eq. (2) is computed using COSPAR International Reference Atmosphere model (CIRA-86) and also using the equation

$v_{\text {in }}=n \times\left(2.6 \times 10^{-15} \times M^{-1 / 2}\right)$.
The neutral density $n$ and the mean molecular mass $M$ are taken from CIRA-86. From Eq. (1), the ratio of successive echo amplitudes could be estimated

$A_{t}(t+\Delta t) / A_{0}(t)=\exp \left(-\frac{16 \pi^{2} D \Delta t}{\lambda^{2}}\right)$.

The effective radar interpulse period $(t)$ was $4 \mathrm{~ms}$ for the present observation. After rearranging and substituting the values of $\Delta t$ and $\lambda$, the radar wavelength $(5.66 \mathrm{~m}), D$, the ambipolar diffusion coefficient is given as

$D=-50.8 \times \ln \left(\frac{A_{t}(t+\Delta t)}{A_{0}(t)}\right)$,

where the time $\Delta t$ corresponds to the time taken by the meteor echo amplitude to become half of its initial amplitude, i.e. $A_{0} / 2$. Equation (5) reduces to:

$D=\frac{\lambda^{2}}{16 \pi^{2} \tau_{1 / 2}} \ln (2)$,

where $\tau_{1 / 2}$ is the half amplitude decay time. Thus, by measuring $\tau_{1 / 2}$ of the meteor signal, it is possible to estimate $T$ by substituting $D$ from Eq. (6) in Eq. (2). This parameter, in turn, could also be expressed using the atmospheric temperature $(T)$ and pressure $(P)$, as shown by Jones and Jones (1990)

$D=K_{a m b} \frac{T^{2}}{P}$,

where $K_{a m b}$ is the proportionality constant and specific details about $K_{a m b}$ have been outlined by Hocking et al. (1997) and Chilson et al. (1996). Hocking et al. (1997) have demonstrated application of this theory to determine the parameter $X^{0}=T / P^{1 / 2}$ and showed that experimental measurements of this parameter using meteor decay times agree reasonably well with CIRA estimates of $X^{0}$. In our approach, the diffusion coefficient is expressed in terms of molecular weight and collision frequency, as it is shown in Eq. (2). The value of $\tau_{1 / 2}$ is typically in the range of 0.01 to $00.5 \mathrm{~s}$ for a radar operating in the range of $30-50 \mathrm{MHz}$ (Hocking et al., 1997).

\section{Results}

\subsection{Meteor occurrence characteristics}

Figure 2 shows the day-to-day variations of the meteor occurrence rate recorded during the period of 16-20 November restricted to the LT of 22:30 to 05:30 on each day. There is a spectacular four-fold increase in the number of meteors observed during the night of 17-18 November 1999. During the non-shower days, the day-to-day variation is not usually very significant.

Figure 3 shows the height variation of the meteor occurrence rate observed during the LT of 22:30-05:30 on 17-18 November 1999, which incidentally is the peak period of meteor activity. The height of occurrence of the meteor trail is 


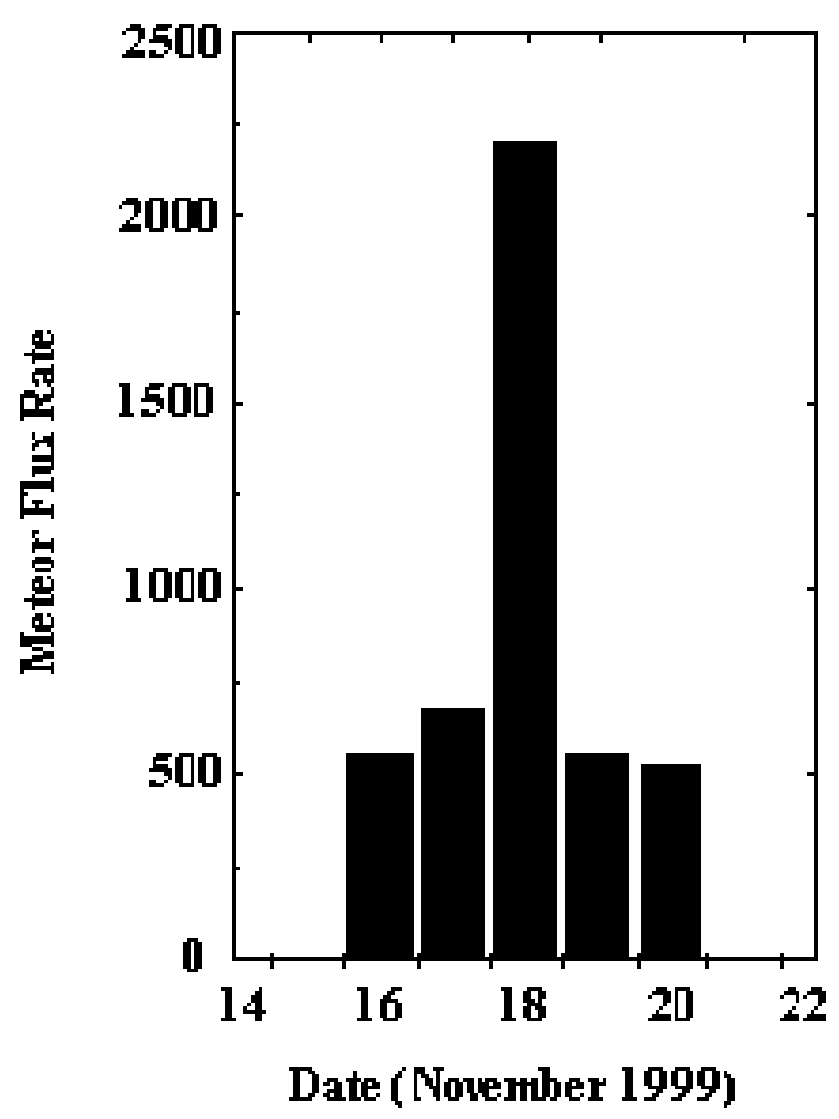

Fig. 2. Day-to-day variation of the rate of formation of meteor trails during LMS period.

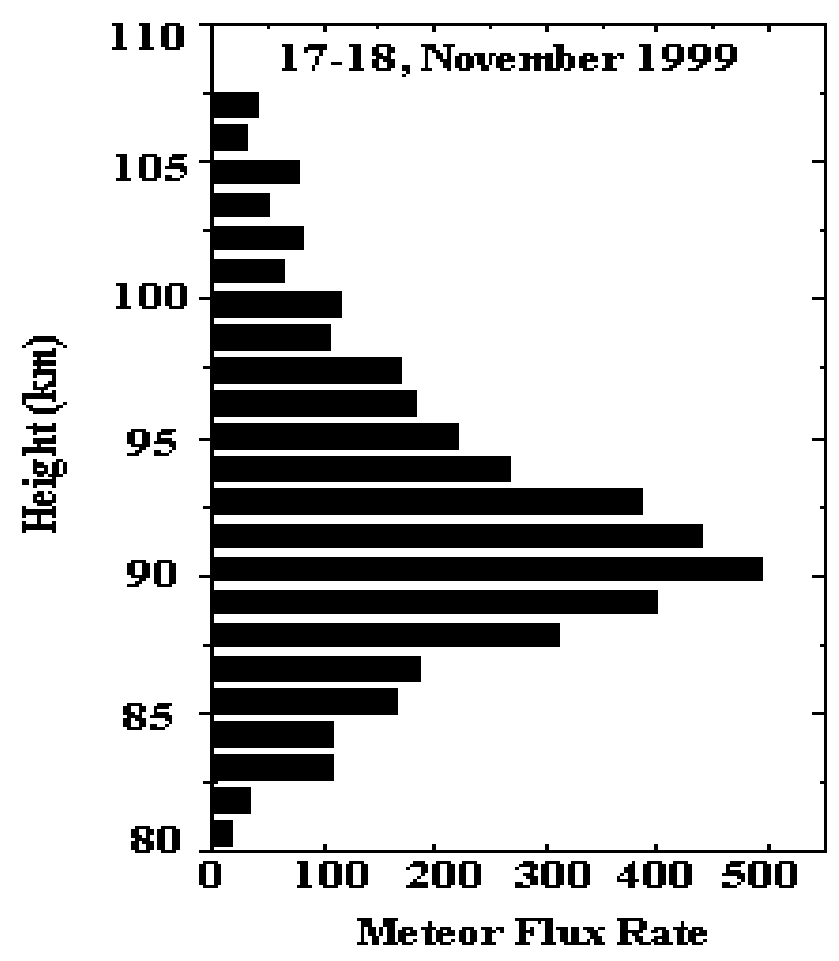

Fig. 3. The altitude distribution of meteor recorded on $17-18$ November 1999.

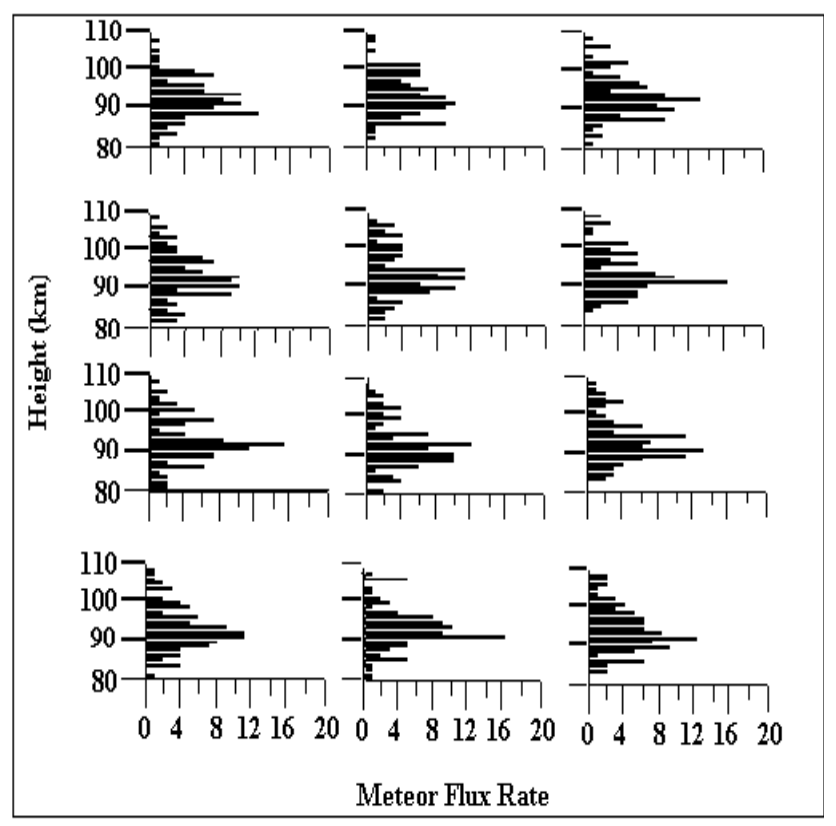

Fig. 4. Altitude distribution of meteor recorded during successive 10-min intervals between 04:00-06:00 LT on 17-18 November 1999.

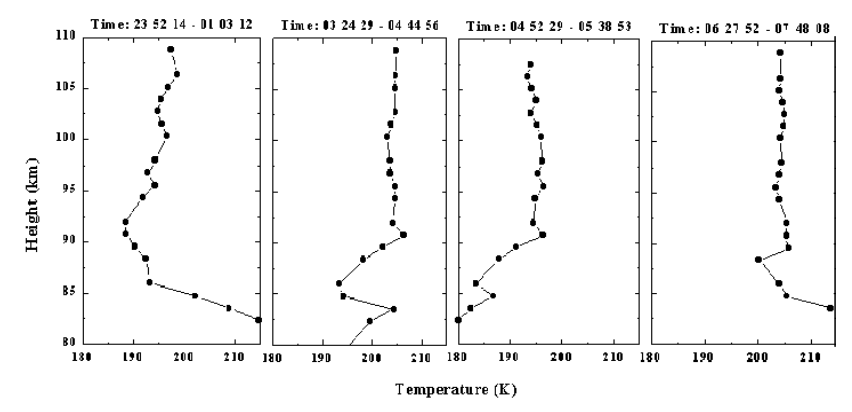

Fig. 5. Temporal variation of temperature profiles obtained on 1718 November 1999.

computed from the zenith angle of the radar beam and slant ranges of the echo. Observations made with both the EW or NS beams showed a peak in the histogram at $90.2 \mathrm{~km}$, and this agrees well with the height of maximum of meteor fluxes. The height of the peak meteoric flux is similar to what one usually encounters in the case of random meteors, should they enter from the same location.

Figure 4 is similar to Fig. 3, but for shorter intervals of time during the LMS events, i.e. between 04:00-06:00 LT for every $10 \mathrm{~min}$. It is interesting to note that, although the altitude distribution in Fig. 4 is similar to that of Fig. 3, the distribution extended to larger heights during some time intervals. The geocentric velocity and the composition of meteoroid variation imply that large meteoroids ablate at higher altitudes and, hence, the occurrence of trails at greater heights during some intervals would mean the presence of more meteoroids of a relatively larger mass in the Leonid stream. 


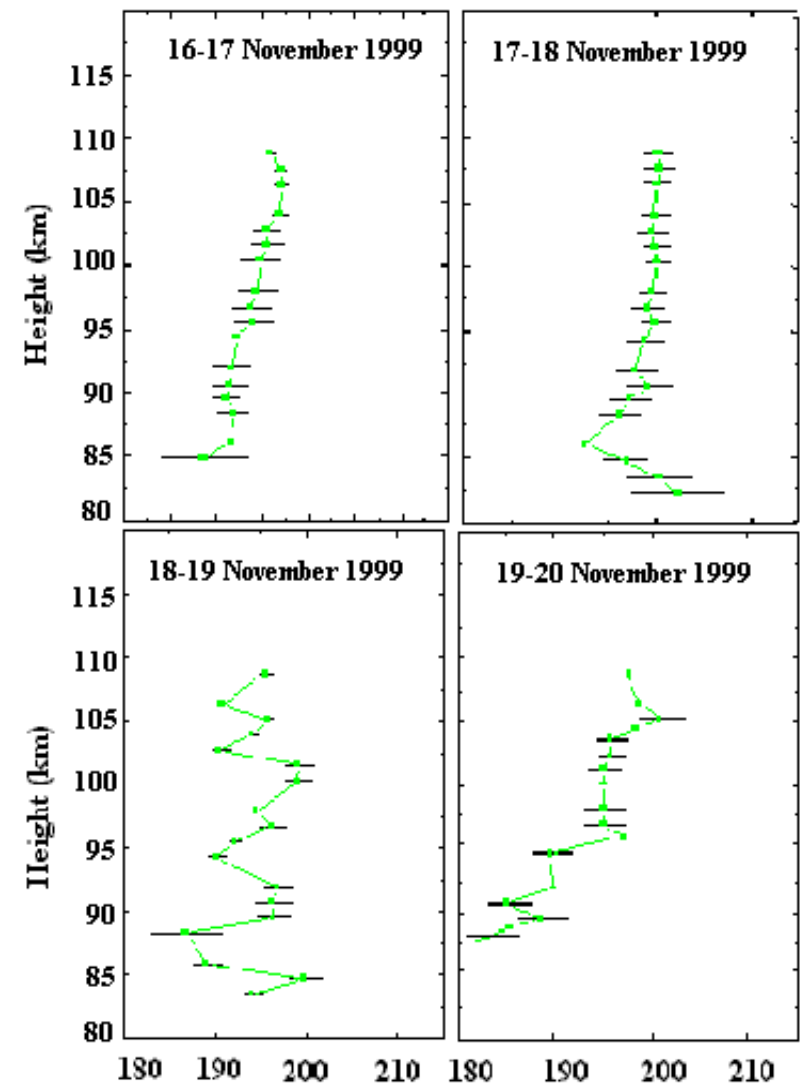

Fig. 6. Day-to-day variation of the lower thermosphere temperature profile.

\subsection{Temperature estimates}

Figure 5 shows the height profiles of the mean temperature during the post-midnight period deduced from meteor trails. The figure shows two important features:

1. The minimum value of temperature is found to be varying between 190-200 K and the height region at which this occurs has been noted to be between $85-97 \mathrm{~km}$. Thus, the temporal variation found in temperature explains the consistency of the technique in bringing further details about overall thermal structure of the lower thermosphere region.

2. The temperature above $90 \mathrm{~km}$ remained almost steady with height during 03:24:29-07:48:08 LT when compared with the profile obtained during 23:52:1401:03:12 LT wherein it showed a wave-like structure riding on a mean temperature. Further, the height of minimum temperature during 23:52:14-01:03:12 LT was found to be at $92 \mathrm{~km}$ with a steep downward gradient, whereas during other times it shifted to lower heights. These results appear to be peculiar to the specific period of observations and are discussed later.

Figure 6 shows the day-to-day variation of the average temperature profile obtained for each day during the entire LMS period with the horizontal lines representing the
17-18 Novem ber, 1999

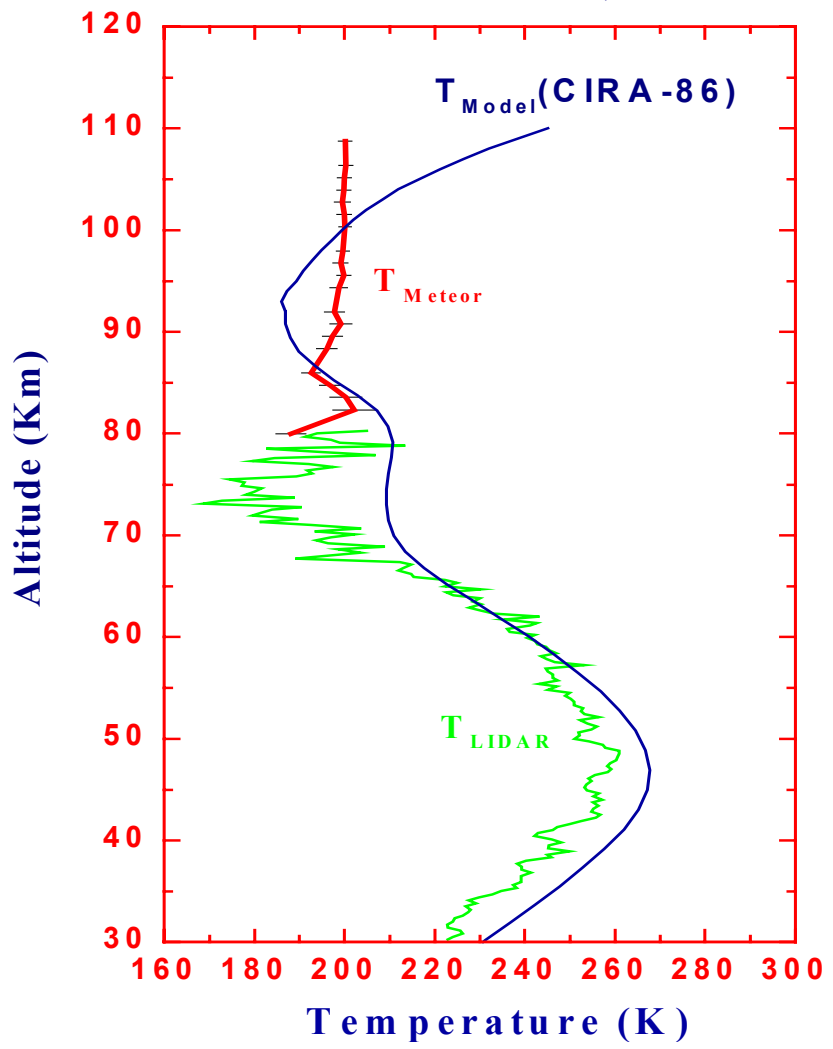

Fig. 7. Temperature profile obtained from meteor trace augmented with the temperature obtained using LIDAR and comparison with the CIRA-86.

standard deviation. During the night of 16-17 November, the temperature showed a gradual increase from $\sim 190 \mathrm{~K}$ at $85 \mathrm{~km}$ to $198 \mathrm{~K}$ at $105 \mathrm{~km}$, while on 17-18 November a well defined minimum was registered at $\sim 85 \mathrm{~km}$ of $\sim 193 \mathrm{~K}$ and increased to $\sim 200 \mathrm{~K}$ at $\sim 110 \mathrm{~km}$. The height region of 90 $110 \mathrm{~km}$ was more or less isothermal. The night of 18-19 November showed an oscillatory structure with amplitudes varying in the range of $15 \mathrm{~K}$ to $5 \mathrm{~K}$ at different altitudes. During the night of 19-20 November, though some oscillatory feature could be perceived, there had been a steady increase from $\sim 182 \mathrm{~K}$ at $87 \mathrm{~km}$ to $200 \mathrm{~K}$ at $105 \mathrm{~km}$.

Figure 7 shows the average of the temperature profiles derived from the LIDAR data between the LT 20:30-05:30 and meteor data using MST radar obtained between the LT 22:30-07:40 LT during 17-18 November 1999. Below $83 \mathrm{~km}$, the temperature decreased with decreasing altitude at the rate of $2 \mathrm{~K} / \mathrm{km}$ and merged with the LIDAR measured temperature, which had nearly the same trend up to $75 \mathrm{~km}$. The temperature above $87 \mathrm{~km}$ increased with height up to $90 \mathrm{~km}$ at a rate of $1.6 \mathrm{~K} / \mathrm{km}$ and above $90 \mathrm{~km}$, it remained almost steady up to $110 \mathrm{~km}$. The errors involved in these estimates are within $\pm 20 \mathrm{~K}$ when the neutral densities and molecular weight are taken from the CIRA-86 model. However, the model provides only an average climatological condition and the deviation from the actual conditions would nat- 


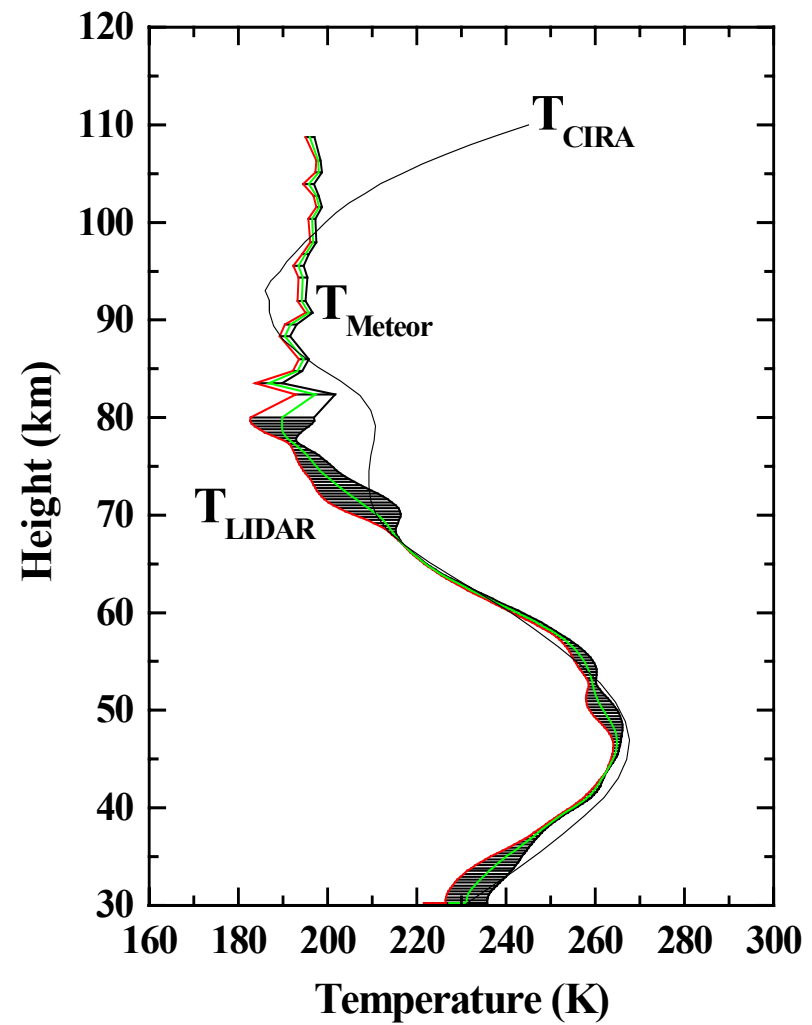

Fig. 8. Average temperature profile obtained from meteor trace augmented with the average temperature obtained using LIDAR and comparison with the CIRA-86.

urally be reflected in the estimates. It is known that on several occasions the deviation could be as large as $40 \mathrm{~K}$. The LIDAR temperature observations, which are more realistic since they depend only on the relative densities, show the height of temperature minimum at about $75 \mathrm{~km}$, above which the temperature increases by $10-15 \mathrm{~K}$ for about $3 \mathrm{~km}$ and above $78 \mathrm{~km}$, the temperature remains more or less constant. The CIRA-86 model agrees very well with the observed profiles between $57 \mathrm{~km}$ and $65 \mathrm{~km}$. Below $85 \mathrm{~km}$, the CIRA- 86 model overestimates the temperatures, whereas above $85 \mathrm{~km}$, the model underestimates the temperatures. Since the estimated temperature using the meteor trail agrees well with independent estimates from a LIDAR providing continuity, the results shown in Fig. 7 are believed to prove the validity of the method of retrieval of temperature profiles using meteor trails, and this could be a valuable means of extending the maximum height of the temperature profiles at least up to $110 \mathrm{~km}$. The average profile obtained using LIDAR for the month of November in '98 and ' 99 is plotted with the average temperature retrieved from the meteor data using MST radar, together with the CIRA-86 model in Fig. 8. The results presented in this figure confirm the results of 17-18 November 1999 presented in Fig. 7. Figure 9 shows the range of diffusion coefficient with each height. The range of variation is $2.75 \pm 0.075 \mathrm{~m}^{2} / \mathrm{s}$ at $90 \mathrm{~km}$, where maximum fall of meteors was observed, as shown in Fig. 9. The curve represents

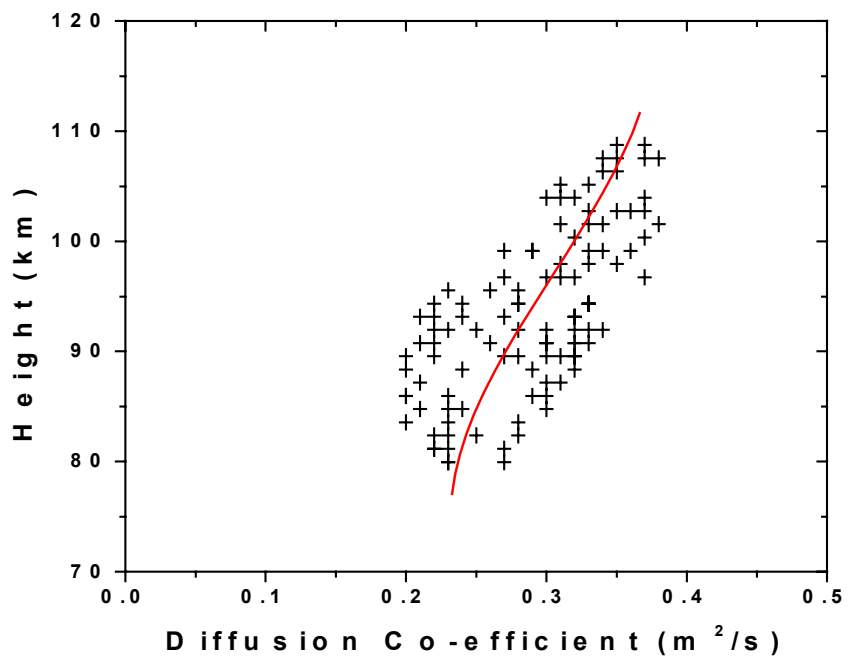

Fig. 9. Scatter plot of Diffusion Coefficient during Leonid Meteor Shower (LMS on 17-18 November) with height.

the smooth fit for the spread in diffusion coefficient found with each height region for the entire shower event on 17-18 November 1999 .

\section{Discussion}

The meteor mode of observation showed that the maximum number of meteors was registered on 17-18 November 1999. It was found to be consistent with the results obtained from $18 \mathrm{MHz} \mathrm{HF}$ radar observations conducted at Trivandrum during the same period and also with observations from the rest of the globe. The MST radar observations have shown that the meteor fluxes on the following and preceding days were only $20 \%$ of the peak shower day. Over Gadanki, the occurrence rate had been quiet high compared to many other places on the globe, mainly due to the fact that the radar beam was almost inclined towards the axis of the Leonid stream position. The altitude distribution has also shown that the maximum occurrence is at $90 \mathrm{~km}$, with an occasional secondary peak at a height of $98-100 \mathrm{~km}$, indicating the presence of meteoroids of larger size associated with the Leonid meteor stream. Since the temperature from the meteor trail diffusion rate was estimated assuming CIRA-86 model neutral densities and molecular weights, any uncertainties in these two parameters additively deviate the temperature estimated, for example, the combined $\pm 20 \%$ (as it is normally found with CIRA-86 model) uncertainty appearing in these two parameters would bring an amount of $\pm 40 \mathrm{~K}$ difference for a temperature of $200 \mathrm{~K}$. On the other hand, if an error occurs in the calculation of $\tau_{1 / 2}$, it is only about $\pm 0.4 \%$ of the estimated temperature, since the time resolution is $4 \mathrm{~ms}$ in our experiment. Further, the variability of $\pm 0.075 \mathrm{~m}^{2} / \mathrm{s}$ in the diffusion coefficient over a base value of $0.275 \mathrm{~m}^{2} / \mathrm{s}$ at $90 \mathrm{~km}$ where the maximum meteor fall, also known as mean meteor peak height, was registered and accounts for the uncertainty of $\pm 15-20 \mathrm{~K}$ in the estimated temperature of $200 \mathrm{~K}$. In fact, 
the range of diffusion coefficient for a given height is seen to be much narrower in our case compared to the previous results reported in literature (Hocking, 1999; Cervara and Reid, 2000; Hocking, 2001). Perhaps, the less variance observed could be characteristic of equatorial MLT region. More detailed analysis with a longer database is planned in the near future. Extreme care has been taken to choose only the exponentially decaying meteor trail. The accuracy of $\pm 20 \mathrm{~K}$ could be taken in the estimated temperature, since the diffusion coefficient suffers a spread of $2.75 \pm 0.075 \mathrm{~m}^{2} / \mathrm{s}$. However, it is realized that the spread in diffusion coefficient is not due to the radar parameters and perhaps, it is due to turbulence and the angle of meteor trace inclination to the Earth's magnetic field.

The temperature profile obtained by combining the profile deduced from the decay rate of meteor echo amplitude in the $80-110 \mathrm{~km}$ altitude, along with that of the temperature measured by the co-located LIDAR, show excellent consistency. It is to be remembered that the temperature profile obtained with LIDAR, having a $300 \mathrm{~m}$ resolution, was smoothed, to obtain the same height resolution $(1.2 \mathrm{~km})$ to make it compatible with that of the meteor trail resolution observed with the MST radar. The temperatures obtained from these two techniques differ from the CIRA-86 (TCIRA). Though the temperatures retrieved are in agreement with the CIRA-86 model in the height region of $55-65 \mathrm{~km}$ (above the stratopause region), there was a large deviation in the region of $68-82 \mathrm{~km}$. It should be kept in mind that the CIRA-86 model provides only a global average (climatology) of the upper atmosphere and is not expected to fully account for local dynamical processes and their contributions to the thermal structure. The equatorial and low-latitude regions are known to be highly dynamic and much of the database has not been included in the formulation of these models due to the paucity of data. In spite of all these limitations, these are the best models available for providing an average picture. In fact, it is felt that the deviations in the present case could be due to inversion of temperature in that region, and the existing models do not usually account for them. Such inversions are found to occur more frequently in the equinox months and less during summer as well as winter months over Gadanki (Sivakumar et al., 2001). Above $100 \mathrm{~km}$, while the CIRA profile shows a monotonic increase, the meteor profile shows extended altitude of the constant temperature in the lower thermosphere. The exact causative mechanisms for such a behaviour call for further investigation, through more coordinated measurements. The profile corresponding to the night of 18-19 November and the night of 19-20 November show quasi-periodic oscillations in temperature with a vertical wavelength of about $7 \mathrm{~km}$, which is typical of internal gravity waves of a few hours in duration. The small deviations from the mean temperature are perhaps associated with gravity waves (Andrews et al., 1987; Somayajulu et al., 1993; Raghava Reddi et al., 1993). There is also an overall agreement with our results and the climatology obtained by Cervara and Reid (2000) and Hocking et al. (2001). Further, the possible role of long- and short-period waves deposit- ing energy and momentum and altering the thermal structure of the MLT region is fairly well understood. Such independent measurements using the atmospheric airglow, Sodium LIDAR measurements and satellite observations in the MLT region (Mulligan and Galligan, 1995; Jun Quian and Gardener, 1995; Shepherd et al., 1997; She and Lowe, 1998; Buriti et al., 2000; Taylor et al., 2001; Hocking et al., 2001) have shown that on several occasions the deviations from the average could be as large as $20-30 \mathrm{~K}$. Recently, Sridharan et al. (1999) showed deviations of as much as 40-50 K between the 'OH' rotational temperatures and the model values during daytime conditions at $\sim 87 \mathrm{~km}$, with varying levels of wave activity. Simulation studies by Liu and Hagan (1998) also reveal such a possibility. The present results from the MST radar in the meteor mode and the LIDAR seem to highlight the role of local dynamical processes. In order to resolve this issue, simultaneous measurements of long- and short-period waves and the other background parameters would be needed and the present results provide the direction for further study.

\section{Summary and conclusions}

The main results obtained from the LMS observations can be summarized as follows:

1. There was a four-fold increase in the hourly meteor flux due to the Leonid meteor stream that occurred during 16-20 November 1999. Further, there were a number of larger mass meteoroids due to the Leonid meteor streams compared to random meteors.

2. The height and value of the minimum temperature in the lower thermosphere could be deduced with a resolution of $1.2 \mathrm{~km}$ and an accuracy of $\pm 20 \mathrm{~K}$ with a fairly good estimate of the mesopause temperature and height.

3. The temperature profile obtained in the lower thermosphere (80-110 km) using an ambipolar diffusion rate of meteor trails is in good continuity with the temperature obtained in the Stratospheric-Mesospheric $(30-80 \mathrm{~km})$ region using LIDAR, thus, enabling the determination of the neutral temperature up to $110 \mathrm{~km}$.

Acknowledgements. The National MST Radar Facility is (NMRF) operated by Department of Space (DOS) with partial funding from Council of Scientific and Industrial Research (CSIR). The first author is grateful to NMRF, for providing the position of Research Associate, which enabled him to carry out the research presented in this paper.

Topical Editor M. Lester thanks a referee for his help in evaluating this paper.

\section{References}

Andrews, G., Holton, J. R., and Leovy, C. B.: Middle atmosphere dynamics, international geophysics dynamics, Int. Geoph. Series, 40, 1987. 
Buriti, R. A., Nakamura, T., Tsuda, T., Fukao, S., Tsutsumi, M., Takahashi, H., and Batista, P. P.: Measopause temperature observed by airglow $\mathrm{OH}$ spectra and meteor echoes at Shigarki (34.9 N, 136.1 E) Japan., Adv. Space. Res., 26, 1005-1008, 2000.

Cervara, A. and Reid, I. M.: Comparison of atmospheric parameter derived from meteor observations with cira, Radio Sci., 35, 833843, 2000.

Chilson, P. B., Czechowsky, P., and Schmidt, G.: Comparison of ambipolar diffusion coefficients in meteor trains using VHF radar and UV Lidar, Geophys. Res. Lett., 23, 2745-2748, 1996.

Cira 1986, COSPAR, International Reference Atmosphere, 1986.

Greenhow, J. S. and Neufeld, E. L.: The diffusion of ionized meteor trails in the upper atmosphere, J. Atmos. Terr. Phys., 6, 133-140, 1955.

Hocking, W. K.: Temperatures using radar meteor decay times, Geophys. Res.Lett., 26, 3297-3300, 1999.

Hocking, W. K., Fuller, B., and Vandepeer, B.: Real-time determination of meteor related parameter utilizing modern digital technology, J. Atmos. Terr. Phys., 63, 155-169, 2001.

Hocking, W. K., Thayaparan, T., and Jones, J.: Meteor decay times and their use in determining a diagnostic mesospheric temperature-pressure parameter: methodology and one year data, Geophys. Res. Lett., 24, 2977-2980, 1997.

Huxley, L. G. H.: The persistence of meteor trails, Aust. J. Sci. Res., 5, 10-16, 1952.

Jones, W. and Jones, J.: Ionic diffusion in meteor trains, J. Atmos. Terr. Phys., 52, 185-191, 1990.

Juan Quian and Gardener, C. S.: Simultaneous Lidar Measurements of Mesospheric Ca, Ba and Temperature Profiles at Urbana, Illinois, J. Geophys. Res, 100, 7453-7461, 1995.

Kaiser, T. R.: Radio echo studies of meteor ionization, Philos. Mag., 2, Suppl., 495-544, 1953.

Liu, H. L. and Hagan, M. E.: Local heating/cooling of the mesosphere due to gravity wave and tidal coupling, Geophys. Res. Lett., 25, 941-944, 1998.

Mulligan, F. J. and Galligan, J. M.: Mesopause temperatures calculated from the $\mathrm{O}_{2}\left(\mathrm{a}^{1} \Delta g\right)$ twilight air glow emission record at Maynooth (53.2 N, $4 \mathrm{~W})$, Ann. Geophysicae., 13, 558-566, 1995.

Raghava Reddi, C. and Nair, S. M.: Processing and early observations of Indian MST Radar Data in its ST mode of operation, Ind. J. Rad. \& Space Phys., 23, 361-374, 1994.

Raghava Reddi, C. and Nair, S. M.: Meteor trail induced backscatter in MST radar echoes, Geophy. Res. Lett., 25, 473-476, 1998.
Raghava Reddi, C., Rajeev K., and Geetha, R.: Tidal winds in the radio- meteor region over Trivandrum $(8.5 \mathrm{~N}, 77 \mathrm{E})$, J. Atmos. Terr. Phys., 55, 1219-1231, 1993.

Raghava Reddi, C., Rajeev K., and Geetha R.: Daily variation in diffusion coefficient and occurrence rate of radio meteor trails, Ind. J. Rad. \& Phys., 23, 361-379, 1995.

Rao, P. B., Jain, A. R., Kishore, P., Balamuralidhar, P., Damle, S. H., and Viswanathan, G.: Indian MST Radar, 1. System description and Sample Vector Wind measurements in ST mode, Radio Sci., 30, 1125-1138, 1995.

Rao, P. B., Raghunath, K., Bhavanikumar, Y., Sivakumar, V., Jain, A. R., Krishnaiah, M., Mizutani, K., Aoki, T., Yusin M., and Itabe, T.: Proceedings of International Laser Sensing Symposium, Fukui, Japan, 47-50, 1999.

She, C. Y. and Lowe, R. P.: Seasonal temperature variations in the mesopause region at mid-latitude: Comparison of LIDAR and hydroxyl rotational temperatures using WIND II/UARS OH height profiles, J.Atmos.Terr. Phys., 60, 1573-1583, 1998.

Shepherd, M. G., Dudhia, A., Lopez-Puertas, M., and Evans, W. F. J.: Upper mesospheric temperatures in summer: WIND II observations and comparisons, Geopys. Res. Lett, 24, 357-360, 1997.

Sivakumar, V., Bavanikumar, Y., Raghunath, K., Rao, P. B., Krishnaiah, M., Mizutani, K., Aoki, T., Yasui, M., and Itabe, T.: Lidar Measurements of Mesospheric temperature inversion at a low-latitude, Ann. Geophysicae., 19, 1-6, 2001.

Somayajulu, V. V., Cherian, L., Rajeev, K., Geetha Ramkumar, and Raghava Reddi, C.: Mean winds and tidal components during counter electroject events, Geophy. Res. Lett., 20, 1443-1446, 1993.

Sridharan, R., Taori, A., Gurubaran, S., Rajaram, R., and Shepherd, M. A.: First results on daytime mesopause $\mathrm{OH}$ rotational temperatures using ground based photometry from equatorial latitudes, J. Atmos. Terr. Phys., 61, 1131-1142, 1999.

Taylor, M. J., Pendleton, W. R. Jr., Liu, H.-L., She, C. Y., Gardner, L. C., Roble, R. G., and Vasoli, V.: Large amplitude perturbations in mesospheric $\mathrm{OH}$ meinel and $87 \mathrm{~km}$ Na Lidar temperatures around the autumnal equinox, Geophys. Res. Lett., 28, 1899-1902, 2001.

Tsutsumi, M., Suda, T., and Nakamura, T.: Temperature fluctuation near the mesopause inferred from meteor observations with the middle and upper atmosphere radar, Radio Sci., 29, 599-610, 1994. 